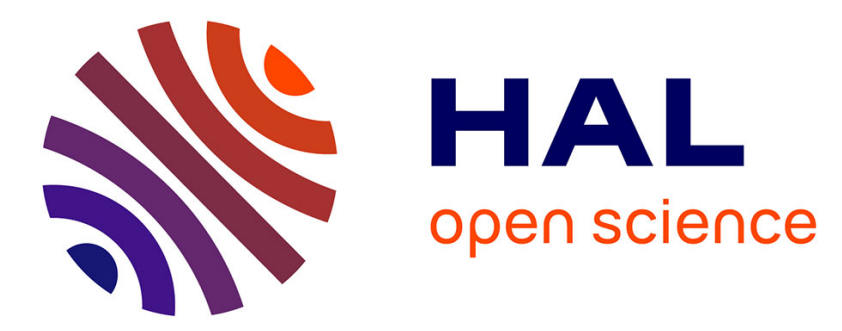

\title{
When is a Compound Energy not a Compound Energy? A Critique of the 2-Sublattice Order/Disorder Model
}

\author{
Nigel Saunders
}

\section{To cite this version:}

Nigel Saunders. When is a Compound Energy not a Compound Energy? A Critique of the 2-Sublattice Order/Disorder Model. Calphad, 1996, 10.1016/s0364-5916(97)00011-4 . hal-03349267

\section{HAL Id: hal-03349267 \\ https://hal.science/hal-03349267}

Submitted on 20 Sep 2021

HAL is a multi-disciplinary open access archive for the deposit and dissemination of scientific research documents, whether they are published or not. The documents may come from teaching and research institutions in France or abroad, or from public or private research centers.
L'archive ouverte pluridisciplinaire HAL, est destinée au dépôt et à la diffusion de documents scientifiques de niveau recherche, publiés ou non, émanant des établissements d'enseignement et de recherche français ou étrangers, des laboratoires publics ou privés.

\section{(1) (1) $\$$}

Distributed under a Creative Commons Attribution - NonCommercial - NoDerivatives $\mid 4.0$ 


\title{
WHEN IS A COMPOUND ENERGY NOT A COMPOUND ENERGY? A CRITIQUE OF THE 2-SUblatTICE ORDER/Disorder MODEL
}

\author{
N.Saunders \\ Thermotech Ltd, Surrey Technology Centre, The Surrey Research Park \\ Guildford, GU2 5YG, U.K.
}

\begin{abstract}
In recent years an extension of the 2-sublattice model has been used to model ordering transformations in systems such as $\mathrm{Ni}-\mathrm{Al}$ and Ti-Al. The model provides a means by which the Gibbs energy of both the ordered and disordered phases can be represented using a 'single' equation thus allowing a continuous change in Gibbs energy to be obtained between the ordered and disordered states. This is an attractive proposition as it permits second order transformations to be considered within the scope of readily accessible models in CALPHAD software packages. However, it can be demonstrated that there are some fundamental flaws in the model, particularly when asymmetric ordering energies are used. This leads to the existence of a residual, extraneous Gibbs energy in the disordered state originating from the ordering parameters. In the most recent expositions of the 2-sublattice order/disorder model the residual energy is empirically removed but this leads to the position where it is possible that the Gibbs energy which is actually calculated for the fully ordered state of a compound such as an $A B$ or $A_{3} B$ type to be quite different from that actually specified for $G_{A B}^{\text {ord }}$ or $G_{A_{3} B}^{\text {ord }}$, hence the title of the present paper.
\end{abstract}

\section{Introduction}

The two-sublattice order disorder model (2SLOD) originates from around 1985. The first time the present author was introduced to it was via an unpublished report by Sundman ${ }^{1}$. This treatment was then used by Gros ${ }^{2}$ for Ti-Al, Ansara et $a l^{3}$ for Ni-Al and the present author for the metastable $\mathrm{L}_{2}$, $\delta$ ' phase in $\mathrm{Al}-\mathrm{Li}-\mathrm{Zr}^{4}$. The treatment was then modified and further work was presented on ordering systems $^{5,6,7}$. The present paper will take the reader through the original derivation of the model and the origin of residual, extraneous energies arising from the use asymmetrical ordering energies will be discussed and its effect demonstrated. The subsequent modification of the model ${ }^{5,6,7}$ will then be discussed and a sample calculation shown where the Gibbs energy calculated for the ordered phase is not as specified in the Gibbs energy parameters. The reason for this will be discussed and its origins explained. 


\section{General Gibbs Energy Equations}

\subsection{Simple Redlich-Kister substitutional mode}

The Gibbs energy of a disordered substitutional phase is given by

$$
\mathrm{G}_{\mathrm{m}}=\sum_{\mathrm{i}} \mathrm{x}_{\mathrm{i}} \mathrm{G}_{\mathrm{i}}^{\mathrm{o}}+\mathrm{RT} \sum_{\mathrm{i}} \mathrm{x}_{\mathrm{i}} \log _{\mathrm{e}} \mathrm{x}_{\mathrm{i}}+\sum_{\mathrm{i}} \sum_{\mathrm{j}>\mathrm{i}} \mathrm{x}_{\mathrm{i}} \mathrm{x}_{\mathrm{j}} \sum_{\mathrm{v}} \Omega_{\mathrm{ij}}^{\mathrm{v}}\left(\mathrm{x}_{\mathrm{i}}-\mathrm{x}_{\mathrm{j}}\right)^{\mathrm{v}}
$$

where $G_{i}^{o}$ is the Gibbs energy of the phase in the pure component and $\Omega_{\mathrm{ij}}^{\mathrm{v}}$ is a binary interaction parameter dependent on the value of $\mathrm{v}$.

\subsection{Sublattice model for a phase with 2 sublattices}

The Gibbs energy of a 2-sublattice phase with the formula $(A, B)_{m}(A, B)_{p}$ can be given by the general equation

$$
\mathrm{G}=\mathrm{G}^{\mathrm{o}}+\mathrm{G}_{\mathrm{mix}}^{\mathrm{ideal}}+\mathrm{G}_{\mathrm{mix}}^{\mathrm{xs}}
$$

where $\mathrm{G}^{\circ}$ is the reference energy contribution of the pure components of the phase to the Gibbs energy, $G_{\text {mix }}^{\text {ideal }}$ is the ideal mixing contribution and $G_{\text {mix }}^{\mathrm{xs}}$ is the Gibbs excess energy contribution. $G^{\circ}$ is given by

$$
\mathrm{G}^{\mathrm{o}}=\mathrm{y}_{\mathrm{A}}^{1} \mathrm{y}_{\mathrm{A}}^{2} \Delta \mathrm{G}_{\mathrm{A}: \mathrm{A}}^{\mathrm{o}}+\mathrm{y}_{\mathrm{A}}^{1} \mathrm{y}_{\mathrm{B}}^{2} \Delta \mathrm{G}_{\mathrm{A}: \mathrm{B}}^{\mathrm{o}}+\mathrm{y}_{\mathrm{B}}^{1} \mathrm{y}_{\mathrm{A}}^{2} \Delta \mathrm{G}_{\mathrm{B}: \mathrm{A}}^{\mathrm{o}}+\mathrm{y}_{\mathrm{B}}^{1} \mathrm{y}_{\mathrm{B}}^{2} \Delta \mathrm{G}_{\mathrm{B}: \mathrm{B}}^{\mathrm{o}}
$$

where $y_{A}^{1}, y_{B}^{2}$ etc. denote site fraction occupations of $A$ and $B$ on sublattice 1 and 2 respectively. $\mathrm{G}_{\text {mix }}^{\text {ideal }}$ is given by

$$
\mathrm{G}_{\text {mix }}^{\text {ideal }}=R T\left[m\left(y_{A}^{1} \log _{e} y_{A}^{1}+y_{B}^{1} \log _{e} y_{B}^{1}\right)+p\left(y_{A}^{2} \log _{e} y_{A}^{2}+y_{B}^{2} \log _{e} y_{B}^{2}\right)\right]
$$

The Gibbs excess energy of mixing is given by

$$
\mathrm{G}_{\text {mis }}^{\mathrm{xs}}=\mathrm{y}_{\mathrm{A}}^{1} \mathrm{y}_{\mathrm{B}}^{1} \mathrm{y}_{\mathrm{A}}^{2} \mathrm{~L}_{\mathrm{A}, \mathrm{B}: \mathrm{A}}+\mathrm{y}_{\mathrm{A}}^{1} \mathrm{y}_{\mathrm{B}}^{1} \mathrm{y}_{\mathrm{B}}^{2} \mathrm{~L}_{\mathrm{A}, \mathrm{B}: \mathrm{B}}+\mathrm{y}_{\mathrm{A}}^{1} \mathrm{y}_{\mathrm{A}}^{2} \mathrm{y}_{\mathrm{B}}^{2} \mathrm{~L}_{\mathrm{A}: \mathrm{A}, \mathrm{B}}+\mathrm{y}_{\mathrm{B}}^{1} \mathrm{y}_{\mathrm{A}}^{2} \mathrm{y}_{\mathrm{B}}^{2} \mathrm{~L}_{\mathrm{B}: \mathrm{A}, \mathrm{B}}
$$

and further to this some site fraction dependence to these parameters can be added such that

$$
\begin{aligned}
& \mathrm{L}_{\mathrm{A}, \mathrm{B}: \mathrm{A}}=\mathrm{y}_{\mathrm{A}}^{1} \mathrm{y}_{\mathrm{B}}^{1} \mathrm{y}_{\mathrm{A}}^{2} \sum_{\mathrm{v}} \mathrm{L}_{\mathrm{A}, \mathrm{B}: \mathrm{A}}^{\mathrm{v}}\left(\mathrm{y}_{\mathrm{A}}^{1}-\mathrm{y}_{\mathrm{B}}^{1}\right)^{\mathrm{v}} \\
& \mathrm{L}_{\mathrm{A}, \mathrm{B}: \mathrm{B}}=\mathrm{y}_{\mathrm{A}}^{1} \mathrm{y}_{\mathrm{B}}^{1} \mathrm{y}_{\mathrm{B}}^{2} \sum_{\mathrm{v}}^{\mathrm{v}} \mathrm{L}_{\mathrm{A}, \mathrm{B}: \mathrm{B}}^{\mathrm{v}}\left(\mathrm{y}_{\mathrm{A}}^{1}-\mathrm{y}_{\mathrm{B}}^{1}\right)^{\mathrm{v}} \\
& \mathrm{L}_{\mathrm{A}: \mathrm{A}, \mathrm{B}}=\mathrm{y}_{\mathrm{A}}^{1} \mathrm{y}_{\mathrm{A}}^{2} \mathrm{y}_{\mathrm{B}}^{2} \sum_{\mathrm{v}}^{\mathrm{v}} \mathrm{L}_{\mathrm{A}: \mathrm{A}, \mathrm{B}}^{\mathrm{v}}\left(\mathrm{y}_{\mathrm{A}}^{2}-\mathrm{y}_{\mathrm{B}}^{2}\right)^{\mathrm{v}} \\
& \mathrm{L}_{\mathrm{B}: \mathrm{A}, \mathrm{B}}=\mathrm{y}_{\mathrm{B}}^{1} \mathrm{y}_{\mathrm{A}}^{2} \mathrm{y}_{\mathrm{B}}^{2} \sum_{\mathrm{v}}^{\mathrm{v}} \mathrm{L}_{\mathrm{B}: \mathrm{A}, \mathrm{B}}^{\mathrm{v}}\left(\mathrm{y}_{\mathrm{A}}^{2}-\mathrm{y}_{\mathrm{B}}^{2}\right)^{\mathrm{v}}
\end{aligned}
$$

These are the basic general equations used in the 2SLOD model for a binary system and can be expanded to a many component system by adding similar terms for components C,D,E...etc. 


\section{2-Sublattice Order/Disorder Model}

\subsection{The Original derivation of the 2SLOD Model}

In a crystalline phase, the sublattice model implies that crystallographically distinct sublattices exist with the inherent assumption that preferential occupation of these sublattices can occur. It was subsequently demonstrated by Sundman ${ }^{1}$ and later Ansara et al. ${ }^{3}$ that conditions could be set on the parameters such that an order-disorder transformation could be modelled in a phase with two sublattices. One of the first phases to be considered was an $A_{3} B$ ordered compound. In such a circumstance the sublattice formula $(\mathrm{A}, \mathrm{B})_{3}(\mathrm{~A}, \mathrm{~B})$ can be applied and the possible values for site fractions related to mole fractions are given in Fig.1. The dashed lines denoted $\mathrm{x}_{\mathrm{B}}=.25, .5$ and .75 show variations in order of the phase while the composition is maintained constant. When these lines cross the diagonal joining $\mathrm{A}_{3} \mathrm{~A}$ and $\mathrm{B}_{3} \mathrm{~B}$ the phase has disordered completely as $\mathrm{y}_{\mathrm{B}}{ }_{\mathrm{B}}=\mathrm{y}_{\mathrm{B}}{ }_{\mathrm{B}}=\mathrm{x}_{\mathrm{B}}$. As the lines go toward the boundary edge the phase orders and, at the side and corners of the composition square, there is complete ordering of $\mathrm{A}$ and $\mathrm{B}$ on the sublattices.

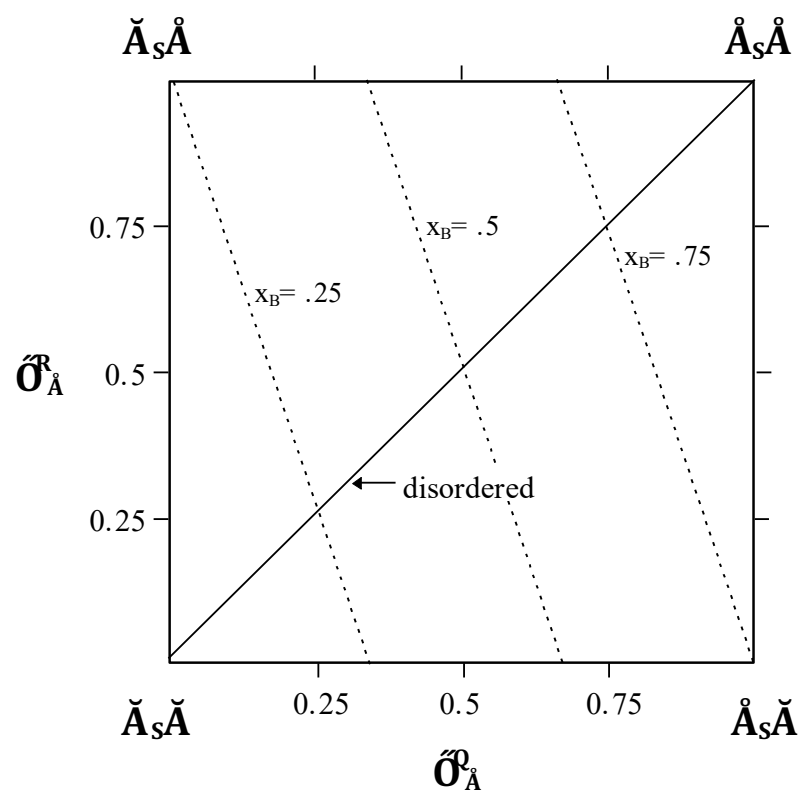

Fig.1 Relationship between site and atomic fractions in the 2 SLOD model for an $\mathrm{A}_{3} \mathrm{~B}$ phase

The two-sublattice order-disorder model (2SLOD) requires first that the Gibbs energy should always have an extremum along the diagonal representing the disordered state with respect to fluctuations in site fractions at constant composition. Further, when the disordered phase is stable this extremum must be a minimum. By arbitrarily setting $\mathrm{G}^{\circ} \mathrm{A}: \mathrm{A}$ and $\mathrm{G}_{\mathrm{B}: \mathrm{B}}^{\circ}$ to be zero, and applying the above conditions, it is possible to define interconnected parameters for the various values of $\mathrm{G}^{\circ} \mathrm{A}: \mathrm{B}$ and $\mathrm{G}^{\circ} \mathrm{B}: \mathrm{A}$ and the excess mixing terms, such that the $\mathrm{A}_{3} \mathrm{~B}$ phase is ordered at low temperature but disorders as the temperature is increased. It should be noted that there is no unique solution to the above simultaneous equations and numerous sets of inter-related parameters can be derived. For the case of an $\mathrm{A}_{3} \mathrm{~B}$ compound one solution gives ${ }^{3}$ 


$$
\begin{aligned}
\mathrm{G}^{\circ} \mathrm{A}: \mathrm{B} & =u_{1} \\
\mathrm{G}^{\circ}{ }_{\mathrm{B}: \mathrm{A}} & =u_{2} \\
\mathrm{~L}^{\circ} \mathrm{A}, \mathrm{B}: \mathrm{A} & =3 u_{1}+u_{2} / 2+3 u_{3} \\
\mathrm{~L}^{\circ}{ }_{\mathrm{A}, \mathrm{B}: \mathrm{B}} & =u_{1} / 2+3 u_{2}+3 u_{3} \\
\mathrm{~L}^{\circ} \mathrm{A}: \mathrm{A}, \mathrm{B} & =u_{1} / 2+u_{3} \\
\mathrm{~L}^{\circ}{ }_{\mathrm{B}: \mathrm{A}, \mathrm{B}} & =u_{2} / 2+u_{3} \\
\mathrm{~L}^{1}{ }_{\mathrm{A}, \mathrm{B}: \mathrm{A}} & =3 u_{4} \\
\mathrm{~L}^{1}{ }_{\mathrm{A}, \mathrm{B}: \mathrm{B}} & =3 u_{5} \\
\mathrm{~L}^{1}{ }_{\mathrm{A}: \mathrm{A}, \mathrm{B}} & =u_{4} \\
\mathrm{~L}^{1}{ }_{\mathrm{B}: \mathrm{A}, \mathrm{B}} & =u_{5} \\
\mathrm{~L}^{\circ}{ }_{\mathrm{A}, \mathrm{B}: \mathrm{A}, \mathrm{B}} & =4 u_{4}-4 u_{5}
\end{aligned}
$$

where $u_{1}, u_{2}$ etc. are variables which can be used in a thermodynamic optimisation process. The above terms give only the ordering contribution to the total energy and to provide the disordered energy it is necessary to add further terms. This is done by using the relationships

$$
\mathrm{x}_{\mathrm{A}}=\mathrm{m} \cdot \mathrm{y}_{\mathrm{A}}^{1}+\mathrm{p} \cdot \mathrm{y}_{\mathrm{A}}^{2} \text { and } \mathrm{x}_{\mathrm{B}}=\mathrm{m} \cdot \mathrm{y}_{\mathrm{B}}^{1}+\mathrm{p} \cdot \mathrm{y}_{\mathrm{B}}^{2}
$$

where $\mathrm{m}$ and $\mathrm{p}$ are the number of sites on sublattice 1 and 2 . It is noted that to retain internal consistency with the Redlich-Kister model $\mathrm{m}+\mathrm{p}=1$. Replacing $\mathrm{x}_{\mathrm{A}}$ and $\mathrm{x}_{\mathrm{B}}$ in eq.1 expanding and comparing with the formula for the two-sublattice model shows that an equivalence in Gibbs energy between the disordered substitutional solid solution and a two-sublattice model can be obtained if the following parameters are used ${ }^{4}$.

$$
\begin{aligned}
\mathrm{G}_{\mathrm{A}: \mathrm{B}}^{\mathrm{o}} & =\mathrm{mp} \cdot \mathrm{L}_{\mathrm{AB}}^{0}+\mathrm{mp}(\mathrm{m}-\mathrm{p}) \cdot \mathrm{L}_{\mathrm{AB}}^{1}+\mathrm{mp}(\mathrm{m}-\mathrm{p})^{2} \cdot \mathrm{L}_{\mathrm{AB}}^{2} \\
\mathrm{G}_{\mathrm{B}: \mathrm{A}}^{\mathrm{o}} & =\mathrm{mp} \cdot \mathrm{L}_{\mathrm{AB}}^{0}-\mathrm{mp}(\mathrm{m}-\mathrm{p}) \cdot \mathrm{L}_{\mathrm{AB}}^{1}+\mathrm{mp}(\mathrm{m}-\mathrm{p})^{2} \cdot \mathrm{L}_{\mathrm{AB}}^{2} \\
\mathrm{~L}_{\mathrm{A}, \mathrm{B}: \mathrm{A}}^{0} & =\mathrm{m}^{2} \cdot \mathrm{L}_{\mathrm{AB}}^{0}+3 \mathrm{~m}^{2} \mathrm{p} \cdot \mathrm{L}_{\mathrm{AB}}^{1}+\mathrm{m}^{2} \mathrm{p}(5 \mathrm{~m}-2 \mathrm{p}) \cdot \mathrm{L}_{\mathrm{AB}}^{2} \\
\mathrm{~L}_{\mathrm{A}, \mathrm{B}: \mathrm{B}}^{0} & =\mathrm{m}^{2} \cdot \mathrm{L}_{\mathrm{AB}}^{0}-3 \mathrm{~m}^{2} \mathrm{p} \cdot \mathrm{L}_{\mathrm{AB}}^{1}+\mathrm{m}^{2} \mathrm{p}(5 \mathrm{~m}-2 \mathrm{p}) \cdot \mathrm{L}_{\mathrm{AB}}^{2} \\
\mathrm{~L}_{\mathrm{A}, \mathrm{B}: \mathrm{A}}^{1} & =\mathrm{m}^{3} \cdot \mathrm{L}_{\mathrm{AB}}^{1}+4 \mathrm{~m}^{3} \mathrm{p} \cdot \mathrm{L}_{\mathrm{AB}}^{2} \\
\mathrm{~L}_{\mathrm{A}, \mathrm{B}: \mathrm{B}}^{1} & =\mathrm{m}^{3} \cdot \mathrm{L}_{\mathrm{AB}}^{1}-4 \mathrm{~m}^{3} \mathrm{p} \cdot \mathrm{L}_{\mathrm{AB}}^{2} \\
\mathrm{~L}_{\mathrm{A}, \mathrm{B}: \mathrm{A}}^{2} & =\mathrm{m}^{4} \cdot \mathrm{L}_{\mathrm{AB}}^{2} \\
\mathrm{~L}_{\mathrm{A}, \mathrm{B}: \mathrm{B}}^{2} & =\mathrm{m}^{4} \cdot \mathrm{L}_{\mathrm{AB}}^{2} \\
\mathrm{~L}_{\mathrm{A}: \mathrm{A}, \mathrm{B}}^{0} & =\mathrm{p}^{2} \cdot \mathrm{L}_{\mathrm{AB}}^{0}+3 \mathrm{p}^{2} \mathrm{~m} \mathrm{~L}_{\mathrm{AB}}^{1}+\mathrm{p}^{2} \mathrm{~m}(5 \mathrm{p}-2 \mathrm{~m}) \cdot \mathrm{L}_{\mathrm{AB}}^{2} \\
\mathrm{~L}_{\mathrm{B}: \mathrm{A}, \mathrm{B}}^{0} & =\mathrm{p}^{2} \cdot \mathrm{L}_{\mathrm{AB}}^{0}-3 \mathrm{p}^{2} \mathrm{~m} \mathrm{~L}_{\mathrm{AB}}^{1}+\mathrm{p}^{2} \mathrm{~m}(5 \mathrm{p}-2 \mathrm{~m}) \cdot \mathrm{L}_{\mathrm{AB}}^{2} \\
\mathrm{~L}_{\mathrm{A}: \mathrm{A}, \mathrm{B}}^{1} & =\mathrm{p}^{3} \cdot \mathrm{L}_{\mathrm{AB}}^{1}+4 \mathrm{p}^{3} \mathrm{~m} \cdot \mathrm{L}_{\mathrm{AB}}^{2} \\
\mathrm{~L}_{\mathrm{B}: \mathrm{A}, \mathrm{B}}^{1} & =\mathrm{p}^{3} \cdot \mathrm{L}_{\mathrm{AB}}^{1}-4 \mathrm{p}^{3} \mathrm{~m} \cdot \mathrm{L}_{\mathrm{AB}}^{2} \\
\mathrm{~L}_{\mathrm{A}: \mathrm{A}, \mathrm{B}}^{2} & =\mathrm{p}^{4} \cdot \mathrm{L}_{\mathrm{AB}}^{2} \\
\mathrm{~L}_{\mathrm{B}: \mathrm{A}, \mathrm{B}}^{2} & =\mathrm{p}^{4} \cdot \mathrm{L}_{\mathrm{AB}}^{2} \\
\mathrm{~L}_{\mathrm{A}, \mathrm{B}: \mathrm{A}, \mathrm{B}}^{\mathrm{o}} & =-24 \mathrm{~m}^{2} \mathrm{p}^{2} \cdot \mathrm{L}_{\mathrm{AB}}^{2}
\end{aligned}
$$


where $\mathrm{L}_{\mathrm{AB}}^{0,1,2}$ are the respective excess parameters from the substitutional model in the Redlich-Kister format. Adding eqs. 6 and 8 together provides the total excess Gibbs energy of the phase both when it is ordered and disordered. This method was used by $\mathrm{Gros}^{2}$, Ansara et al. ${ }^{3}$ and Saunders ${ }^{4}$ and, in general, calculations gave quite reasonable results. However, the model proved to have some flaws. When asymmetrical terms are used for the ordering energies (i.e. $u_{1} \neq u_{2}$ ) they give rise to a residual, extraneous excess Gibbs energy when the phase disorders and there is no longer an equivalence in Gibbs energy between the 2SLOD model and the original disordered phase. This can be demonstrated for a simple $\mathrm{AB}$ system with an allotropic change from $\alpha$ to $\beta$ in the pure elements.

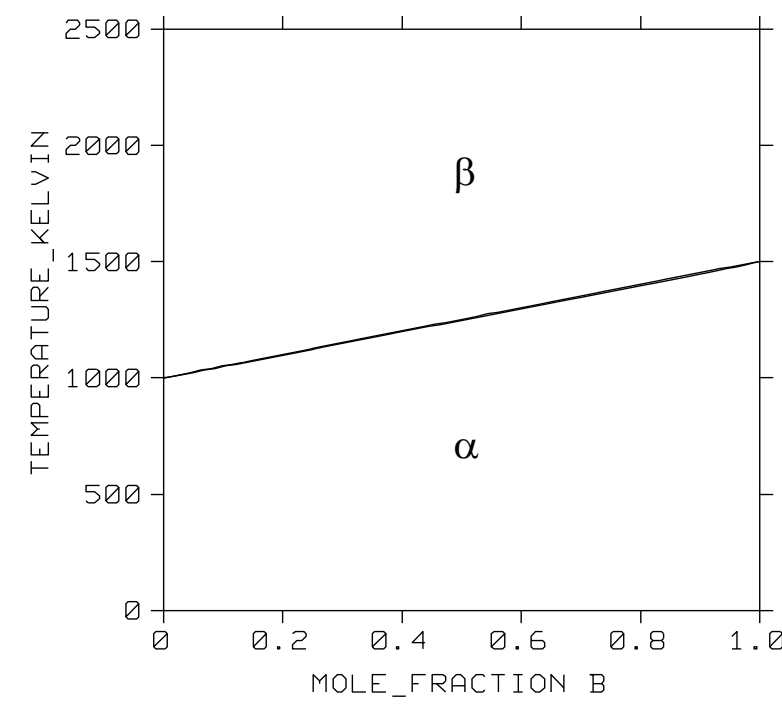

Fig. 2 Simple A-B system with no ordering parameters.

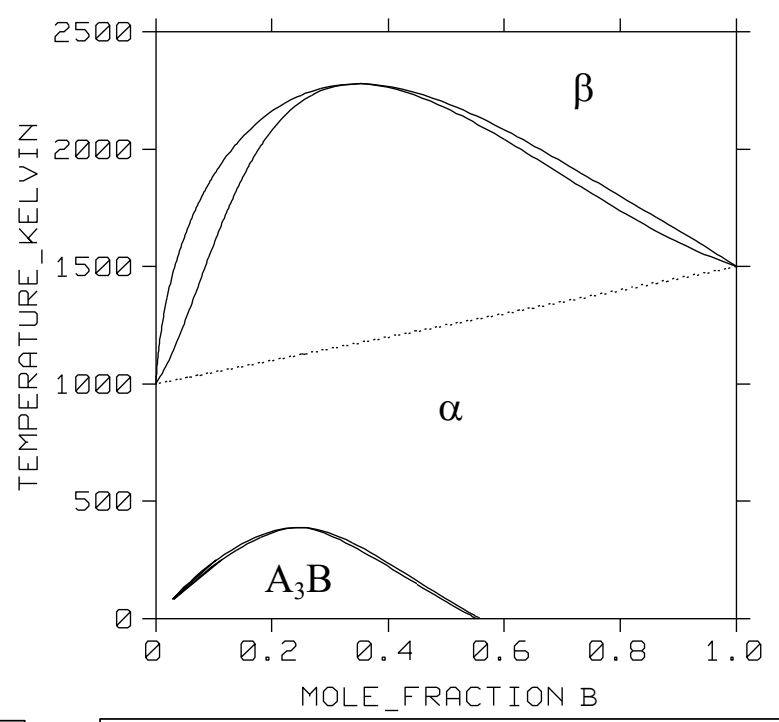

Fig. 3 Simple A-B system with ordering parameters included.

Fig. 2 shows the calculated phase diagram with a simple very thin 2-phase field between $\alpha$ and $\beta$ assuming identical parameters for the mixing parameters of both phases and $u_{1}=u_{2}=u_{3}=u_{4}=u_{5}=0$. Fig. 3 shows the same system but calculated with $u_{1}=-5000 \mathrm{~J} \mathrm{~mol}^{-1}$ and $u_{2}=u_{3}=u_{4}=u_{5}=0$. As can be seen the ordering temperature is rather low but the $\alpha+\beta$ phase boundary has been shifted dramatically because of the residual extraneous energies from the ordered parameters. The reason why these should exist is not immediately obvious but a closer examination of the treatment shows that an additional condition is necessary before the parameters in eq. 6 are derived. This is that $\mathrm{G}^{\mathrm{xs}}=0$ when the phase is disordered. Placing this condition into the derivation gives the following, apparently unique, conditions whereby no residual energies are left on disordering8, $G A: B=G B: A=-G A, B: A=-$ $\mathrm{GA}, \mathrm{B}: \mathrm{B}=-\mathrm{GA}: \mathrm{A}, \mathrm{B}=-\mathrm{GB}: \mathrm{A}, \mathrm{B}$. This turns out to be the same conditions used by the present author4 to give ordering under Bragg-Williams-Gorsky conditions as proposed by Inden ${ }^{9,10,11,12}$.

A further problem arises with the original model in that, although the 2-sublattice model and the Redlich-Kister model can be made equivalent in a binary, this equivalence can be lost in ternary and higher order systems if sub-regular or higher interaction terms are used. This is because of the 'counting' of interactions. It can be shown very straightforwardly that while regular solutions are being used there is complete equivalence between the two models. Substituting values as described in eq. 8 into a 2 -sublattice model (eq.3 and 5) gives the following equation for the Gibbs excess energy of mixing. 


$$
\begin{aligned}
G_{\text {mix }}^{\mathrm{xs}}= & \mathrm{y}_{\mathrm{A}}^{1} \mathrm{y}_{\mathrm{B}}^{2} \mathrm{mp} \mathrm{L}_{\mathrm{AB}}^{\mathrm{o}}+\mathrm{y}_{\mathrm{B}}^{1} \mathrm{y}_{\mathrm{A}}^{2} \mathrm{mp} \mathrm{L}_{\mathrm{AB}}^{\mathrm{o}} \\
& \mathrm{y}_{\mathrm{A}}^{1} \mathrm{y}_{\mathrm{B}}^{1} \mathrm{y}_{\mathrm{A}}^{2} \mathrm{~m}^{2} \mathrm{~L}_{\mathrm{AB}}^{\mathrm{o}}+\mathrm{y}_{\mathrm{A}}^{1} \mathrm{y}_{\mathrm{B}}^{1} \mathrm{y}_{\mathrm{B}}^{2} \mathrm{~m}^{2} \mathrm{~L}_{\mathrm{AB}}^{\mathrm{o}}+\mathrm{y}_{\mathrm{A}}^{1} \mathrm{y}_{\mathrm{A}}^{2} \mathrm{y}_{\mathrm{B}}^{2} \mathrm{p}^{2} \mathrm{~L}_{\mathrm{AB}}^{\mathrm{o}}+\mathrm{y}_{\mathrm{B}}^{1} \mathrm{y}_{\mathrm{A}}^{2} \mathrm{y}_{\mathrm{B}}^{2} \mathrm{p}^{2} \mathrm{~L}_{\mathrm{AB}}^{\mathrm{o}}
\end{aligned}
$$

In the disordered state $\mathrm{y}_{\mathrm{A}}^{1}=\mathrm{y}_{\mathrm{A}}^{2}=\mathrm{x}_{\mathrm{A}}$ and $\mathrm{y}_{\mathrm{B}}^{1}=\mathrm{y}_{\mathrm{B}}^{2}=\mathrm{x}_{\mathrm{B}}$, taking the reference states for pure $\mathrm{A}$ and $\mathrm{B}\left(\mathrm{G}_{\mathrm{A}: \mathrm{A}}^{\mathrm{o}}\right.$ and $\left.\mathrm{G}_{\mathrm{B}: \mathrm{B}}^{\mathrm{o}}\right)$ as equal to zero and substituting into eq. 9 gives the Gibbs excess energy of mixing as

$$
\begin{aligned}
\mathrm{G}_{\text {mix }}^{\mathrm{xs}}= & \mathrm{x}_{\mathrm{A}} \mathrm{x}_{\mathrm{B}} \mathrm{mp} \mathrm{L}_{\mathrm{AB}}^{\mathrm{o}}+\mathrm{x}_{\mathrm{A}} \mathrm{x}_{\mathrm{B}} \mathrm{mp} \mathrm{L}_{\mathrm{AB}}^{\mathrm{o}}+\mathrm{x}_{\mathrm{A}}{ }^{2} \mathrm{x}_{\mathrm{B}} \mathrm{m}^{2} \mathrm{~L}_{\mathrm{AB}}^{\mathrm{o}} \\
& +\mathrm{x}_{\mathrm{A}} \mathrm{x}_{\mathrm{B}}{ }^{2} \mathrm{~m}^{2} \mathrm{~L}_{\mathrm{AB}}^{\mathrm{o}}+\mathrm{x}_{\mathrm{A}}{ }^{2} \mathrm{x}_{\mathrm{B}} \mathrm{p}^{2} \mathrm{~L}_{\mathrm{AB}}^{\mathrm{o}}+\mathrm{x}_{\mathrm{B}}^{2} \mathrm{x}_{\mathrm{A}} \mathrm{p}^{2} \mathrm{~L}_{\mathrm{AB}}^{\mathrm{o}}
\end{aligned}
$$

which becomes

$$
\begin{aligned}
\mathrm{G}_{\text {mix }}^{\mathrm{xs}}= & \mathrm{x}_{\mathrm{A}} \mathrm{x}_{\mathrm{B}} 2 \mathrm{mp} \mathrm{L}_{\mathrm{AB}}^{\mathrm{o}} \\
& +\mathrm{x}_{\mathrm{A}} \mathrm{x}_{\mathrm{B}}\left(\mathrm{x}_{\mathrm{A}} \mathrm{m}^{2} \mathrm{~L}_{\mathrm{AB}}^{\mathrm{o}}+\mathrm{x}_{\mathrm{B}} \mathrm{m}^{2} \mathrm{~L}_{\mathrm{AB}}^{\mathrm{o}}+\mathrm{x}_{\mathrm{A}} \mathrm{p}^{2} \mathrm{~L}_{\mathrm{AB}}^{\mathrm{o}}+\mathrm{x}_{\mathrm{B}} \mathrm{p}^{2} \mathrm{~L}_{\mathrm{AB}}^{\mathrm{o}}\right)
\end{aligned}
$$

as $\mathrm{x}_{\mathrm{A}}+\mathrm{x}_{\mathrm{B}}=1$, eq. 11 reduces again to

$$
\mathrm{G}_{\text {mix }}^{\mathrm{xs}}=\mathrm{x}_{\mathrm{A}} \mathrm{x}_{\mathrm{R}} 2 \mathrm{mp} \mathrm{L}_{\mathrm{AR}}^{\mathrm{o}}+\mathrm{x}_{\mathrm{A}} \mathrm{x}_{\mathrm{R}}\left(\mathrm{m}^{2} \mathrm{~L}_{\mathrm{AR}}^{\mathrm{o}}+\mathrm{p}^{2} \mathrm{~L}_{\mathrm{AR}}^{\mathrm{o}}\right)
$$

which gives

$$
\mathrm{G}_{\text {mix }}^{\mathrm{xs}}=\mathrm{x}_{\mathrm{A}} \mathrm{x}_{\mathrm{R}}\left(\mathrm{m}^{2}+2 \mathrm{mp}+\mathrm{p}^{2}\right) \mathrm{L}_{\mathrm{AR}}^{\mathrm{o}}
$$

as $\mathrm{m}^{2}+2 \mathrm{mp}+\mathrm{p}^{2}=(\mathrm{m}+\mathrm{p})^{2}$ and $\mathrm{m}+\mathrm{p}=1$, eq.13 finally reduces to the regular solution model

$$
\mathrm{G}_{\text {mix }}^{\mathrm{xs}}=\mathrm{x}_{\mathrm{A}} \mathrm{x}_{\mathrm{R}} \mathrm{L}_{\mathrm{AR}}^{\mathrm{o}}
$$

In a multi-component system, if A-B interactions on the sublattices are independent of site occupation on the other sublattice, there is complete equivalence with the substitutional Redlich-KisterMuggianu model. However, if a sub-regular model is used $\mathrm{L}_{\mathrm{A}: \mathrm{A}, \mathrm{B}}^{\mathrm{O}} \neq \mathrm{L}_{\mathrm{B}: \mathrm{A}, \mathrm{B}}^{\mathrm{a}}$ and the situation becomes more complex as A-B interactions are then dependent on the occupation of the complimentary sublattice. Mathematically an equivalence is maintained in the binary case as A-B interactions are governed by the concentration/ratio of A and B. This can be shown for the case of the regular contribution to A-B interactions on sublattice 1 where $\sum \mathrm{G}_{\mathrm{A}, \mathrm{B}: *}$, the total summated interactions of A-B on sublattice 1 , is

$$
\sum \mathrm{G}_{\mathrm{A}, \mathrm{B}: *}=\mathrm{y}_{\mathrm{A}}^{1} \mathrm{y}_{\mathrm{B}}^{1} \mathrm{y}_{\mathrm{A}}^{2}\left(\mathrm{~m}^{2} \mathrm{~L}_{\mathrm{AB}}^{\mathrm{o}}+3 \mathrm{~m}^{2} \mathrm{p} \mathrm{L}_{\mathrm{AB}}^{1}\right)+\mathrm{y}_{\mathrm{A}}^{1} \mathrm{y}_{\mathrm{B}}^{1} \mathrm{y}_{\mathrm{B}}^{2}\left(\mathrm{~m}^{2} \mathrm{~L}_{\mathrm{AB}}^{\mathrm{o}}-3 \mathrm{~m}^{2} \mathrm{p} \mathrm{L} \mathrm{AB}_{\mathrm{AB}}^{1}\right)
$$

which becomes

$$
\sum \mathrm{G}_{\mathrm{A}, \mathrm{B}: *}=\mathrm{x}_{\mathrm{A}}{ }^{2} \mathrm{x}_{\mathrm{B}}\left(\mathrm{m}^{2} \mathrm{~L}_{\mathrm{AB}}^{\mathrm{o}}+3 \mathrm{~m}^{2} \mathrm{pL}_{\mathrm{AB}}^{1}\right)+\mathrm{x}_{\mathrm{A}} \mathrm{x}_{\mathrm{B}}{ }^{2}\left(\mathrm{~m}^{2} \mathrm{~L}_{\mathrm{AB}}^{\mathrm{o}}-3 \mathrm{~m}^{2} \mathrm{pL}_{\mathrm{AB}}^{1}\right)
$$

and

$$
\sum \mathrm{G}_{\mathrm{A}, \mathrm{B}: *}=\mathrm{x}_{\mathrm{A}} \mathrm{x}_{\mathrm{B}}\left[\mathrm{x}_{\mathrm{A}}\left(\mathrm{m}^{2} \mathrm{~L}_{\mathrm{AB}}^{\mathrm{o}}+3 \mathrm{~m}^{2} \mathrm{pL}_{\mathrm{AB}}^{1}\right)+\mathrm{x}_{\mathrm{B}}\left(\mathrm{m}^{2} \mathrm{~L}_{\mathrm{AB}}^{\mathrm{o}}-3 \mathrm{~m}^{2} \mathrm{pL}_{\mathrm{AB}}^{1}\right)\right]
$$


This can be further reduced to

$$
\sum \mathrm{G}_{\mathrm{A}, \mathrm{B}: *}=\mathrm{x}_{\mathrm{A}} \mathrm{x}_{\mathrm{B}}\left[\left(\mathrm{x}_{\mathrm{A}}+\mathrm{x}_{\mathrm{B}}\right) \mathrm{m}^{2} \mathrm{~L}_{\mathrm{AB}}^{\mathrm{o}}+3 \mathrm{~m}^{2} \mathrm{p} \mathrm{L}_{\mathrm{AB}}^{1}\left(\mathrm{x}_{\mathrm{A}}-\mathrm{x}_{\mathrm{B}}\right)\right]
$$

and finally

$$
\sum \mathrm{G}_{\mathrm{A}, \mathrm{B}: *}=\mathrm{x}_{\mathrm{A}} \mathrm{x}_{\mathrm{B}}\left[\mathrm{m}^{2} \mathrm{~L}_{\mathrm{AB}}^{\mathrm{o}}+3 \mathrm{~m}^{2} \mathrm{p} \mathrm{L}_{\mathrm{AB}}^{1}\left(\mathrm{x}_{\mathrm{A}}-\mathrm{x}_{\mathrm{B}}\right)\right]
$$

This is in the form of the sub-regular Redlich-Kister form and when the complete summations are done for all A-B interactions there is equivalence between the Redlich-Kister and 2-sublattice model. However when $\mathrm{C}$ is added to sublattice 2 a further degree of freedom needs to be considered and eq. 15 becomes

$$
\begin{aligned}
\sum \mathrm{G}_{\mathrm{A}, \mathrm{B}:^{*}}= & \mathrm{y}_{\mathrm{A}}^{1} \mathrm{y}_{\mathrm{B}}^{1} \mathrm{y}_{\mathrm{A}}^{2}\left(\mathrm{~m}^{2} \mathrm{~L}_{\mathrm{AB}}^{\mathrm{o}}+3 \mathrm{~m}^{2} \mathrm{pL}_{\mathrm{AB}}^{1}\right)+\mathrm{y}_{\mathrm{A}}^{1} \mathrm{y}_{\mathrm{B}}^{1} \mathrm{y}_{\mathrm{B}}^{2}\left(\mathrm{~m}^{2} \mathrm{~L}_{\mathrm{AB}}^{\mathrm{o}}-3 \mathrm{~m}^{2} \mathrm{pL}_{\mathrm{AB}}^{1}\right) \\
& +\mathrm{y}_{\mathrm{A}}^{1} \mathrm{y}_{\mathrm{B}}^{1} \mathrm{y}_{\mathrm{C}}^{2}\left(\mathrm{~L}_{\mathrm{A}, \mathrm{B}: \mathrm{C}}\right)
\end{aligned}
$$

The total, summed A-B interaction term is now also dependent on the magnitude of A-B interactions when $\mathrm{C}$ occupies the opposite sublattice, effectively a ternary interaction. The question now arises as to what parameter can be used for $\mathrm{L}_{\mathrm{A}, \mathrm{B}: \mathrm{C}}$. If the either of the values $\left(\mathrm{m}^{2} \mathrm{~L}_{\mathrm{AB}}^{\mathrm{o}}+3 \mathrm{~m}^{2} \mathrm{pL}_{\mathrm{AB}}^{1}\right)$ or $\left(\mathrm{m}^{2} \mathrm{~L}_{\mathrm{AB}}^{\mathrm{o}}-3 \mathrm{~m}^{2} \mathrm{pL}_{\mathrm{AB}}^{1}\right)$ are used then the summations clearly do not give eq.19. If an average value is used this will also only summate correctly when $\mathrm{y}_{\mathrm{A}}^{1}=\mathrm{y}_{\mathrm{B}}^{1}$. The value of $\mathrm{L}_{\mathrm{A}, \mathrm{B}: \mathrm{C}}$ must therefore be a more complex function, dependent itself on site occupation of sublattice 2, which is not possible within the present mathematical description of the 2 -sublattice model. The consequence is that, when sub-regular or higher terms are used, there is no longer an equivalence between the 2-sublattice model and the substitutional model in ternary and higher order systems. The situation is rather analogous to the case of the ionic liquid model and the associate model where equivalence can be found in the binary but is lost on extension to ternary and higher order systems ${ }^{13}$.

\subsection{The Modified 2SLOD Model}

Some of the problems with the model were addressed in later work by Dupin ${ }^{6}$ who used a more complex formulation for the ordering parameters. Firstly, the ordering contribution was added straightforwardly to the Redlich-Kister-Muggianu polynomial formula for the disordered phase thus removing potential incompatibility problems between the 2-sublattice and the disordered substitutional models in ternary and higher order systems. Secondly the extraneous excess energies from the ordering parameters were empirically removed such that the excess Gibbs energy due to the ordered parameters became zero on disordering. Generally the Gibbs energy is then expressed as

$$
\mathrm{G}_{\mathrm{m}}=\mathrm{G}_{\mathrm{m}}^{\mathrm{dis}}\left(\mathrm{x}_{\mathrm{i}}\right)+\mathrm{G}_{\mathrm{m}}^{\mathrm{ord}}\left(\mathrm{y}_{\mathrm{i}}^{1} \mathrm{y}_{\mathrm{i}}^{2}\right)-\mathrm{G}_{\mathrm{m}}^{\text {ord }}\left(\mathrm{y}_{\mathrm{i}}^{1}=\mathrm{x}_{\mathrm{i}} ; \mathrm{y}_{\mathrm{i}}^{2}=\mathrm{x}_{\mathrm{i}}\right)
$$


where $G_{m}^{\text {dis }}\left(x_{i}\right)$ is the Gibbs energy contribution of the disordered state given by the substitutional model, $G_{m}^{\text {ord }}\left(y_{i}^{1} y_{i}^{2}\right)$ is the Gibbs energy contribution due to ordering from the 2SLOD model and $\mathrm{G}_{\mathrm{m}}^{\text {ord }}\left(\mathrm{y}_{\mathrm{i}}^{1}=\mathrm{x}_{\mathrm{i}} ; \mathrm{y}_{\mathrm{i}}^{2}=\mathrm{x}_{\mathrm{i}}\right)$ is a term which represents the extraneous excess energy contribution from the ordered parameters when the phase disorders. A more accurate representation of the Ni-Al diagram was achieved by Dupin ${ }^{6}$ using this model and its was further extended to Ni-Al-Cr-Ta and Ni-Al-CrTa. However, it is noted that the accuracy of the calculations still does not approach that which can be achieved using more traditional two-sublattice modelling ${ }^{14,15}$ which treats the ordered and disordered phases separately.

Although, at first sight, the new formalism appears to remove the discrepancies in version 1 of the 2SLOD model, the empirical removal of the extraneous disordered energies from the ordered parameters causes internal inconsistencies in the model. For example, in an ordered compound such as an $\mathrm{AB}$ or $\mathrm{A}_{3} \mathrm{~B}$ type, it is possible that the Gibbs energy which is actually calculated for the fully ordered state is quite different from that specified for $G_{A B}^{\text {ord }}$ or $G_{A_{3} B}^{\text {ord }}$. This can be shown in the following way for an $\mathrm{AB}$ ordered compound. Two calculation were set up following the routines in

Thermo-Calc to describe the 2SLOD model as given in eq.21. In both cases $G_{m}^{\text {dis }}\left(x_{i}\right)$ is taken to be zero, i.e. ideal, and excess energies arise only from the ordering parameters.

\section{$\underline{\text { Case } 1}$}

The following conditions are set as described in section 3.1 for the case where, in the disordered state, there are no residual energies from the ordered parameters

$$
\begin{aligned}
& \mathrm{T}=298.15, \mathrm{x}_{\mathrm{B}}=0.5 \\
& \mathrm{G}_{\mathrm{A} \cdot \mathrm{R}}^{\mathrm{o}}=\mathrm{G}_{\mathrm{R} \cdot \mathrm{A}}^{\mathrm{o}}=-10000 \mathrm{~J} \mathrm{~mol}^{-1} \\
& \mathrm{G}_{\mathrm{A} \cdot \mathrm{A} \mathrm{R}}^{\mathrm{o}}=\mathrm{G}_{\mathrm{R} \cdot \mathrm{A} \mathrm{R}}^{\mathrm{o}}=\mathrm{G}_{\mathrm{AR} \cdot \mathrm{A}}^{\mathrm{o}}=\mathrm{G}_{\mathrm{AR} \cdot \mathrm{R}}^{\mathrm{o}}=10000 \mathrm{~J} \mathrm{~mol}^{-1}
\end{aligned}
$$

The calculation is made and almost $100 \%$ ordering occurs. The Gibbs energy is calculated as $-10000 \mathbf{J ~ m o l}^{-1}$ as would be expected from the compound energy given above. The ordering temperature is $2405.4 \mathrm{~K}$

\section{$\underline{\text { Case } 2}$}

The following conditions are set with equivalences for the ordering parameters after Sundman and Ansara $^{6}$ and Dupin ${ }^{7}$.

$$
\begin{aligned}
& \mathrm{T}=298.15, \mathrm{x}_{\mathrm{B}}=0.5 \\
& \mathrm{G}_{\mathrm{A} \cdot \mathrm{R}}^{\mathrm{o}}=\mathrm{G}_{\mathrm{R} \cdot \mathrm{A}}^{\mathrm{o}}=-10000 \mathrm{~J} \mathrm{~mol}^{-1} \\
& \mathrm{G}_{\mathrm{A} \cdot \mathrm{A} \mathrm{R}}^{\mathrm{o}}=\mathrm{G}_{\mathrm{R} \cdot \mathrm{A} \mathrm{R}}^{\mathrm{o}}=\mathrm{G}_{\mathrm{A} \mathrm{R} \cdot \mathrm{A}}^{\mathrm{o}}=\mathrm{G}_{\mathrm{A} \mathrm{R} \cdot \mathrm{R}}^{\mathrm{o}}=0 \mathrm{~J} \mathrm{~mol}^{-1}
\end{aligned}
$$

The calculation is made and almost $100 \%$ ordering occurs but is less complete than for case 1 . The Gibbs energy is calculated as $\mathbf{- 5 0 0 0} \mathrm{J} \mathrm{mol}^{-1}$ which is half the compound energy given above and the ordering temperature is reduced to $1202.7 \mathrm{~K}$. 
The only difference between Case 1 and 2 is that the interaction parameters are changed. However, this should not affect the Gibbs energy as the phase is almost 100\% ordered in both cases and the energy arising from the interaction terms is negligible. It is clear, therefore, that the 2SLOD model does not necessarily calculate the Gibbs energy as defined by the compound energy in the $\mathrm{G}_{\mathrm{A}: \mathrm{B}}^{\mathrm{B}}$ or

$\mathrm{G}_{\mathrm{B}: \mathrm{A}}^{\mathrm{o}}$ term, hence the title of the present paper. The reason for this is the residual energies from the ordering terms are removed whether the phase is ordered or disordered. In case 1 there are no residual energies and, therefore, the correct value for compound is calculated, while in case 2 there are residual energies arising from the ordering parameters.

\section{Discussion and Conclusions}

The 2SLOD model has fundamental flaws which under most circumstances give rise to a residual, extraneous Gibbs energy in the disordered state originating from the ordering parameters. The most recent derivation of the model 'empirically' removes these energies but this leads to an internal inconsistency in the model and means that the parameters used to define the Gibbs energy of the phase do not necessarily reflect the true energy which is actually calculated. They should, therefore, be taken only as 'effective' operational terms which may, in themselves, have limited significance. The question subsequently arises as to whether the features as shown above are scientifically desirable in a Gibbs energy model. The answer to this must be no and it is noted that the author is unaware of any other model that exhibits such a feature. There should, therefore, be some compelling reason for using this model rather than (1) a more conventional model or (2) looking for alternative, more fundamental, ordering treatments.

The most significant advantage of the 2SLOD model over a conventional 2-sublattice description, where the ordered and disordered phases are treated separately, is that the Gibbs energy of the disordered and ordered states form a continuum. It is, therefore, possible to model a second order transformation which, at present, is very difficult to do using other readily available models in CALPHAD software packages. Therefore, where a second order transformation needs to be modelled it may be that the 2SLOD model is the only solution. In such cases it is strongly recommended that the parameter restrictions which give rise to BWG conditions ${ }^{4}$, and with no residual energies, are used. This is currently being done for the B2 phase in Ti-Al-X systems where quite good success is obtained in equilibrium calculations ${ }^{16}$. However, it should be stressed that in the present author's experience for first order transformations in Ti-Al-X systems ${ }^{16}$ and Ni-based superalloys ${ }^{14,15,17}$ it is possible by using a conventional 2-sublattice treatment to very accurately predict (i) phase boundaries (more accurately than with the 2SLOD model) (ii) site fraction occupations of the various elements and (iii) ordering energies in multi-component systems. The conclusion, therefore, is that there is very little, if anything, to be gained by using the 2SLOD model for systems which exhibit first order transformations.

At the moment it is difficult to see why the 2SLOD model should be used as a basis for 'theoretical' modelling of ordering transformations. It is fundamentally phenomenological in nature and the parameter derivations used in recent years do not differentiate between structures ${ }^{7}$. Hence the same parameters can be used to describe the $\mathrm{A}_{3} \mathrm{~B}$ in the $\mathrm{BCC}$-based $\mathrm{D}_{3}$ structure, the HCP-based $\mathrm{DO}_{19}$ structure and the FCC-based L1 2 structure. Further, it is not predictive in its own right. For example, 
once the parameters are found which give phase boundaries for a $\mathrm{DO}_{3}$ phase it is not be possible to predict the phase boundaries for a B32 or B2 phase unless the parameters are related back to a more fundamental model, for example the BWG or Cluster Variation Method (CVM) ordering models.

Recently Sundman and Mohri ${ }^{5}$ have expanded the 2SLOD model to include 4-sublattices and implemented it in such a way that it provided results which closely match those obtained by CVM. They did this by considering composition independent interaction energies, equivalent to a classical Bragg-Williams ${ }^{18}$ treatment, and including a short-range order contribution (sro) via tetrahedron clusters. The disorder contribution was then a regular solution and the ordering arose only from next neighbour interactions. This therefore remains a very basic ordering treatment and to model complex ordering systems such as Ti-Al it is almost certainly necessary to include at least $3^{\text {rd }}$ nearest neighbour interchange energies ${ }^{19}$. The treatment did however show that the short range order contribution could be handled by considering the clusters as species using a treatment similar to that used for molecularlike species in a gas.

It will be interesting to see if treatments based on sublattice models can be made more fundamental. It is clear that quite explicit conditions must be imposed on the parameters and until now it has only been used for quite simple ordered structures such as $\mathrm{L}_{2}$ and $\mathrm{B} 2$. It will be necessary to include more than 4 sublattices for complex ordered phases which may be superstructures of these simple types and to consider more than $1^{\text {st }}$ or $2^{\text {nd }}$ nearest neighbour energies. Further to this, the choice of clusters for the sro part must relate back to the sublattice model itself and it is difficult to see how the more complex clusters which can be handled by CVM models can be reconciled with the sublattice models used so far.

\section{$\underline{\text { References }}$}

1 B.Sundman, unpublished report (1985)

2 J.P.Gros, Dr.Ing.Thesis, l'Institut National Polytechnique de Grenoble, France, (1987)

3 I.Ansara, B.Sundman and P.Willemin, Acta Metall. 36, 977 (1988)

4 N.Saunders, Z.Metallkde. 80, 894 (1989)

5 B.Sundman and T.Mohri, Z Metallkde. 81, 251 (1990)

6 B.Sundman and I.Ansara, unpublished research (1992)

7 N.Dupin, Ph.D.Thesis, l'Institut National Polytechnique de Grenoble, France, (1995)

8 L.Chandrasekaran and N.Saunders, unpublished research, (1989)

9 G.Inden, Z.Metallkde. 66, 577 (1975)

10 G.Inden, Z.Metallkde. 66, 648 (1975)

11 G.Inden, Z.Metallkde. 68, 529 (1977)

12 G.Inden, J.de Physique, Colloque C7, 373, (1977)

13 M.Hillert, B.Jansson, B.Sundman and J.Ågren, Met.Trans.A 16A, 261, (1985)

14 N.Saunders, Phil.Trans.A 351, 543, (1995)

15 N.Saunders, in Superalloys 1996 eds.R.D.Kissinger, D.J.Deye, D.L.Anton, A.D.Cetel, M.V.Nathal, T.M.Pollock and D.A.Woodford, p101. TMS, Warrendale, PA (1996)

16 N.Saunders, in Titanium '95: Science and Technology, eds.P.Bleckinsop, W.J.Evans and H.M.Flower, p2167. Inst. Materials, London (1996)

17 A.P.Miodownik and N.Saunders, in Applications of Thermodynamics in the Synthesis and Processing of Materials, eds.P.Nash and B.Sundman, p91. TMS, Warrendale, PA (1995)

18 W.L.Bragg and E.J.Williams, Proc.Roy.Soc., A145, 69, (1934)

19 D.Pettifor, private communication to the author (1996) 